\title{
Erratum to: more complications in uncemented compared to cemented hemiarthroplasty for displaced femoral neck fractures: a randomized controlled trial of 201 patients, with one year follow-up
}

Sophie Moerman ${ }^{1 *}$, Nina M. C. Mathijssen ${ }^{1}$, Dieu D. Niesten ${ }^{1}$, Roeland Riedijk², Willard J. Rijnberg ${ }^{3}$, Sander Koëter ${ }^{4}$, Keetie Kremers van de Hei ${ }^{4}$, Wim E. Tuinebreijer ${ }^{5}$, Tim L. Molenaar ${ }^{1}$, Rob G. H. H. Nelissen ${ }^{6}$ and Anne J. H. Vochteloo ${ }^{7}$

\section{Erratum}

After publication of this article [1] it came to our attention that the author Wim E. Tuinebreijer was incorrectly included as Wim E. Tuinebreier. The correct spelling of this author name is included in this erratum and updated in the original article.

\section{Author details \\ 'Department of Orthopaedics, Reinier de Graaf Group, Reinier de Graafweg 5 , 2625 AD Delft, The Netherlands. ${ }^{2}$ Tergooi hospital, Hilversum, The Netherlands. ${ }^{3}$ Rijnstate Hospital, Arnhem, The Netherlands. ${ }^{4}$ Canisius Wilhelmina Hospital, Nijmegen, The Netherlands. ${ }^{5}$ Department of Surgery/ Traumatology, Erasmus MC, Rotterdam, The Netherlands. 'Leiden University Medical Center, Leiden, The Netherlands. ${ }^{7}$ Centre for Orthopaedic Surgery OCON, Hengelo, The Netherlands.}

Received: 10 May 2017 Accepted: 7 July 2017

Published online: 17 July 2017

\section{Reference}

1. Moerman S, et al. More complications in uncemented compared to cemented hemiarthroplasty for displaced femoral neck fractures: a randomized controlled trial of 201 patients, with one year follow-up. BMC Musculoskelet Disord. 2017:18:169. doi:10.1186/s12891-017-1526-0.

\footnotetext{
* Correspondence: sophie.moerman@rdgg.nl

1 Department of Orthopaedics, Reinier de Graaf Group, Reinier de Graafweg 5, 2625 AD Delft, The Netherlands

Full list of author information is available at the end of the article
} 